\title{
Metabolic adaptation and trophic strategies of soil bacteria-C1- metabolism and sulfur chemolithotrophy in Starkeya novella
}

\author{
Ulrike Kappler* and Amanda S. Nouwens \\ School of Chemistry and Molecular Biosciences, The University of Queensland, St Lucia, QLD, Australia
}

Edited by:

Per Bengtson, Lund University, Sweden

Reviewed by:

Levente Bodrossy, CSIRO MArine and Atmospheric Research,

Australia

Yasuyoshi Sakai, Kyoto University, Japan

\section{*Correspondence:}

Ulrike Kappler, School of Chemistry and Molecular Biosciences, The University of Queensland, Cooper Rd Bldg 76, St. Lucia, QLD 4072, Australia

e-mail: u.kappler@uq.edu.au
The highly diverse and metabolically versatile microbial communities found in soil environments are major contributors to the global carbon, nitrogen, and sulfur cycles. We have used a combination of genome -based pathway analysis with proteomics and gene expression studies to investigate metabolic adaptation in a representative of these bacteria, Starkeya novella, which was originally isolated from agricultural soil. This bacterium was the first facultative sulfur chemolithoautotroph that was isolated and it is also able to grow with methanol and on over 39 substrates as a heterotroph. However, using glucose, fructose, methanol, thiosulfate as well as combinations of the carbon compounds with thiosulfate as growth substrates we have demonstrated here that contrary to the previous classification, $S$. novella is not a facultative sulfur chemolitho- and methylotroph, as the enzyme systems required for these two growth modes are always expressed at high levels. This is typical for key metabolic pathways. In addition enzymes for various pathways of carbon dioxide fixation were always expressed at high levels, even during heterotrophic growth on glucose or fructose, which suggests a role for these pathways beyond the generation of reduced carbon units for cell growth, possibly in redox balancing of metabolism. Our results then indicate that $S$. novella, a representative of the Xanthobacteraceae family of methylotrophic soil and freshwater dwelling bacteria, employs a mixotrophic growth strategy under all conditions tested here. As a result the contribution of this bacterium to either carbon sequestration or the release of climate active substances could vary very quickly, which has direct implications for the modeling of such processes if mixotrophy proves to be the main growth strategy for large populations of soil bacteria.

Keywords: carbon metabolism, methylotrophy, methanol, chemolithotrophy, thiosulfate, soil bacteria, Starkeya novella

(n)

\section{INTRODUCTION}

Agriculturally used soil surfaces account for approximately $37 \%$ of the Earth's total land area and thus the biogeochemical processes taking place in this vast ecosystem can affect the entire biosphere. Soil environments are also major contributors to global element cycles including the sulfur and carbon cycle both of which are important for agriculture (Kertesz et al., 2007; Kolb, 2009; Yuan et al., 2012).

As a result, the biological processes in soils contribute significantly to the release or consumption of a variety of climate active substances which include volatile sulfur compounds as well as methanol and carbon dioxide, both of which are important in the global carbon cycle and influence atmospheric chemistry (Kolb, 2009; Hunger et al., 2011). Methanol is known to contribute to ozone formation and is primarily produced and released by growing plants or the decay of plant materials. However, only a fraction of the methanol that is produced enters the atmosphere $\left(\sim 4.9 \times 10^{12} \mathrm{~mol} \mathrm{year}^{-1}\right)$ while the rest is oxidized to carbon dioxide by methylo- and methanotrophic bacteria before being released (Kolb, 2009). The microbially mediated interconversion of compounds with a beneficial effect on atmospheric processes into ones with potentially detrimental effects has become a major focus of research into microbial metabolic activities as these processes can significantly influence the composition of atmospheric gases.

At present at least 56 bacterial species isolated from soils have been reported to be capable of degrading methanol, and the majority of these appear to be facultative methylotrophs (Kolb, 2009), suggesting that they are capable of switching to other growth modes which can include (chemolitho)autotrophy and heterotrophy using other reduced carbon compounds.

While historically bacteria have been classified as either autotrophs (i.e., fixing carbon dioxide) or heterotrophs based on their ability to grow on defined media in the laboratory, it has recently been proposed that these clear cut divisions may not accurately reflect natural processes (Eiler, 2006; Kolb, 2009). In nature bacteria likely encounter multiple energy and/or carbon sources at the same time, and in most cases these would not be present in high concentrations (Eiler, 2006; Kolber, 2007). Consequently, a "mixotrophic" growth strategy would increase 
the ability of bacteria to draw on multiple sources of energy rather than relying solely on hetero- or autotrophy at any given time (Eiler, 2006). However, little data on these processes are available at present despite their potential to affect microbial activities that contribute to carbon sequestration and/or the release of climate active substances.

In order to enhance understanding of trophic strategies in often highly versatile soil bacteria, we have investigated the differential expression of key metabolic pathway in the soil bacterium Starkeya novella (formerly Thiobacillus novellus) (Kelly et al., 2000) as a function of available growth substrates. S. novella was the first facultative sulfur oxidizing chemolithoautotroph to be isolated but is also capable of utilizing various $\mathrm{C} 1$ compounds, including methanol, for growth as well as at least 39 reduced carbon sources including sugars, amino sugars, amino acids, and organic acids (Starkey, 1935; Chandra and Shethna, 1977; Kelly et al., 2000; Kappler et al., 2012). This combination of metabolic traits should allow $S$. novella to contribute to both the biological sulfur and carbon cycles in various ways and depending on the prevailing growth mode its metabolic activities could either enhance carbon sequestration or the release of carbon dioxide. However, it has never been investigated if or how this bacterium makes use of the many possible growth modes that it is able to adopt. The only published studies of the consumption of sulfur compounds and sugars in S. novella yielded contradictory results reporting either simultaneous consumption or sequential use of energy sources (Lejohn et al., 1967; Leefeldt and Matin, 1980; Matin et al., 1980; Perez and Matin, 1980). The ability of S. novella to grow on $\mathrm{C} 1$ compounds also remains largely unexplored, with the only existing data being a report of robust growth on methanol and formate (Chandra and Shethna, 1977) and while S.novella sulfur metabolism was studied intensively in the 1960s and 70s (Aleem, 1965; Charles and Suzuki, 1966a,b; Oh and Suzuki, 1977a,b; Katayama Fujimura and Kuraishi, 1980), only some data that included molecular detail have been reported to date. In the last 15 years the presence of a sox gene cluster (soxAX-soxYZBCD $F$ ) encoding a thiosulfate oxidizing multienzyme complex and a gene locus encoding a sulfite oxidizing enzyme (sigEorf1-sorAB) have been reported (Kappler et al., 2000, 2001, 2004).

Here we have used a combination of genomic, proteomic and gene expression data to identify key metabolic pathways involved in dissimilatory sulfur oxidation, utilization of $\mathrm{C} 1$ and other carbon compounds or growth in the presence of both types of energy sources with the aim of unraveling the relative activities of carbon sequestering and releasing pathways in S. novella.

\section{METHODS}

\section{STRAINS AND GROWTH CONDITIONS}

Starkeya novella DSMZ506 ${ }^{\mathrm{T}}$ was routinely grown at $28^{\circ} \mathrm{C}$ on modified DSMZ69 medium as described elsewhere (Wilson and Kappler, 2009). The DSMZ69 medium base was supplemented with either $100 \mathrm{mM}$ methanol $(\mathrm{M}, \mathrm{MeOH})$ or $40 \mathrm{mM}$ thiosulfate (TS) or a combination of the two (TS/M, TS/MeOH). For strain maintenance DSMZ69 -TS agar plates supplemented with $40 \mu \mathrm{g} / \mathrm{ml}$ nalidixic acid were used. For proteomics experiments, liquid cultures were grown under microaerophilic conditions
( $100 \mathrm{ml}$ medium in $250 \mathrm{ml}$ shake flasks, $200 \mathrm{rpm}, 28^{\circ} \mathrm{C}$ ) to midlate exponential growth phase, harvested by centrifugation and stored at $-80^{\circ} \mathrm{C}$ until further use. For RNA isolation cultures were grown to mid-exponential growth phase before preservation with RNA protect bacteria reagent (Qiagen).

\section{MOLECULAR METHODS}

Standard methods were used throughout (Ausubel, 1995). Routine PCR used GoTaq Mastermix green (Promega) according to the manufacturer's instructions. Genomic DNA was isolated using the DNAZOL reagent (Life Technologies). Culture samples for RNA isolation ( 2 or $3 \mathrm{ml}$ ) were preserved in 1 vol of RNA protect bacteria reagent (Qiagen), RNA was isolated using the RNAspin mini Kit (GE Healthcare). RNA samples were tested for gDNA contamination using PCR, only samples that failed to produce a product after 34 cycles of amplification were used for cDNA synthesis. cDNA was prepared with Superscript III (Life Technologies) using $0.5 \mu \mathrm{g}$ of DNA-free RNA. Primer sets for use in qRT-PCR experiments (product size: $100 \mathrm{bp}$, annealing temperatures $>60^{\circ} \mathrm{C}$ ) (Table S1) were designed using Vector NTI Advance 11 (Life Technologies). qRT-PCR experiments were essentially performed as in (Kappler et al., 2005; Kappler and Nouwens, 2013) using the SYBR green Mastermix (Applied Biosystems) and $10 \mu \mathrm{L}$ reactions. Experiments were carried out at the University of Queensland SCMB realtime PCR facility using an epMotion workstation (Eppendorf) and an Applied Biosystems 7900 realtime PCR machine.

\section{PROTEOMICS TECHNIQUES}

Cell pellets for use in MS/MS proteomics experiments were resuspended in $8 \mathrm{M}$ urea, $50 \mathrm{mM}$ ammonium bicarbonate $\mathrm{pH} 8.0$ and disrupted using a French Pressure Cell (Aminco; 3 passes, $12000 \mathrm{psi})$. Samples were centrifuged $(20,000 \times \mathrm{g}, 10 \mathrm{~min})$ followed by determination of protein concentrations using the $2 \mathrm{D}$ Quant Kit (GE Healthcare). Between 1 and $2 \mathrm{mg}$ of protein were then incubated with $5 \mathrm{mM}$ DTT $\left(30 \mathrm{~min}, 45^{\circ} \mathrm{C}\right)$ followed by treatment with $25 \mathrm{mM}$ iodoacetamide $(30 \mathrm{~min}$, in the dark, RT). Samples were diluted 1 in 4 with $50 \mathrm{mM}$ ammonium bicarbonate $\mathrm{pH} 8.0$ before Trypsin Gold seq grade (Promega) was added in a 1:100 ratio. After 4 hours at $37^{\circ} \mathrm{C}$ the same amount of trypsin was added again and samples incubated overnight at $37^{\circ} \mathrm{C}$.

Offline 2D LC-MS/MS analyses were used for shotgun proteomics as described in (Kappler and Nouwens, 2013). The equivalent of $500 \mu \mathrm{g}$ of digested protein was diluted 1:1 with $5 \% \mathrm{ACN} / 0.1 \%$ TFA and desalted with a C18 Toptip (Glygen, USA). Desalting used $100 \% \mathrm{ACN}$ to wet resin $(3 \times 150 \mu \mathrm{l})$, $5 \%$ ACN $/ 0.1 \%$ TFA $(3 \times 150 \mu \mathrm{l})$ for tip equilibration and wash steps, and $80 \% \mathrm{ACN} / 0.1 \%$ TFA $(2 \times 150 \mu \mathrm{l})$ for elution. Eluted peptides were concentrated in a SpeedVac and resuspended in $0.5 \%$ acetic acid $/ 2 \%$ ACN. Peptides $(180 \mu \mathrm{g})$ were separated on an Agilent 1100 chromatography system using a Zorbax 300 -SCX column $(5 \mu \mathrm{m}, 4.6 \times 50 \mathrm{~mm})$ (Agilent) at $0.5 \mathrm{ml} / \mathrm{min}$ (gradient: 0-5 min, 0\% buffer B; 5-25 min, 0-50\% buffer B; 25$27 \mathrm{~min}, 50-80 \%$ buffer B; $27-32 \mathrm{~min}, 80 \%$ buffer B; 32-34 min $80-0 \%$ buffer $\mathrm{B}$, where buffer $\mathrm{A}=0.5 \%$ acetic acid $/ 2 \% \mathrm{ACN}$ and buffer $\mathrm{B}=0.5 \%$ acetic acid $/ 2 \% \mathrm{ACN} / 250 \mathrm{mM}$ ammonium 
acetate). Fractions $(250 \mu \mathrm{l})$ were collected in a microtitre plate before pooling (final no. of pooled fractions: 10) and desalted using ZipTips (Millipore, Massachusetts, USA) followed by separation using reversed-phase chromatography on a Shimadzu Prominence nanoLC system. All fractions were analyzed in triplicate at a flow rate of $30 \mu \mathrm{l} / \mathrm{min}$. Samples were first loaded on an Agilent C18 trap $(0.3 \times 5 \mathrm{~mm}, 5 \mu \mathrm{m})$ for $8 \mathrm{~min}$, followed by separation on a Vydac Everest C18 (300 A, $5 \mu \mathrm{m}, 150 \mathrm{~mm} \times 150 \mu \mathrm{m})$ column at a flow rate of $1 \mu \mathrm{l} / \mathrm{min}$. Peptides were separated on a gradient of 3-40\% buffer B over $67 \mathrm{~min}$ followed by $40-98 \%$ buffer $\mathrm{B}$ over $3 \mathrm{~min}$, where buffer $\mathrm{A}=1 \% \mathrm{ACN} / 0.1 \% \mathrm{FA}$ and buffer $\mathrm{B}=80 \% \mathrm{ACN} / 0.1 \% \mathrm{FA}$ was used. Eluted peptides were directly analyzed on a TripleTof 5600 instrument (ABSciex) using a Nanospray III interface. Gas and voltage settings were adjusted as required. MS-ToF scan across m/z 350-1800 was performed for $0.5 \mathrm{~s}$ followed by data-dependent acquisition of 20 peptides with intensity above 100 counts across m/z 40-1800 (0.05 s per spectra) using "high sensitivity" MS/MS and rolling collision energy.

MS data from triplicates of pooled samples were combined and searched using ProteinPilot v4.2 (ABSciex, Forster City CA) with the Paragon Algorithm using fasta formatted protein sequences for the finished $S$. novella genome obtained from JGI. Search parameters included trypsin as enzyme, iodoacetamide as cysmodification, emphasis on biological modifications and "thorough" search setting. Only proteins with a ProteinPilot confidence score of $95 \%$ or better (estimated global FDR $5 \%$ or lower) were accepted. Further data analysis used the integrated microbial genomes resource (IMG; img.jgi.doe.gov) (Markowitz et al., 2012).

\section{BIOINFORMATICS}

Analysis of the $S$. novella genome to identify pathways and enzyme systems was performed using the KEGG pathways database (www.genome.jp/kegg/pathway.html) (Kanehisa et al., 2012), comparative analyses used biocyc.org (biocyc.org/) (Caspi et al., 2012), and IMG (img.jgi.doe.gov/) (Markowitz et al., 2012). In some cases BLASTP (Altschul et al., 1997) was used to confirm the absence or presence of genes not identified in other database searches

\section{RESULTS}

The high degree of metabolic flexibility that is apparent in the large number of growth substrates that can be used by $S$. novella is also very clearly reflected in the pathways encoded in its genome (Kappler et al., 2012). A partial analysis of S. novella initial glucose catabolism and its respiratory chain was carried out as part of the original genome analysis and revealed the presence of a pentose phosphate pathway (PPP) as well as an Entner Doudoroff (ED) pathway for the degradation of glucose (Figure 1A) while the absence of phosphofructokinase (EC 2.7.1.146) in the glycolysis pathway indicates that its primary purpose is gluconeogenesis. In addition the presence of multiple oxygen-dependent terminal reductases in the $S$. novella respiratory chain was noted (Kappler et al., 2012). However, there were no previous analyses of any enzymes or pathways involved in pyruvate metabolism, methanol degradation, and only two gene clusters encoding sulfur oxidizing enzymes had been previously described.

\section{PYRUVATE METABOLISM}

The routes by which pyruvate produced by glucose breakdown can be utilized include oxidation to lactate via the action of one of several putative lactate dehydrogenases (Snov_0154, Snov_0198, Snov_1738, Snov_3299, Snov_4339) or to acetyl-CoA by a pyruvate dehydrogenase complex (genes Snov_1789 to Snov_1795).

Acetyl-CoA can then enter the TCA cycle, which in S. novella also includes a glyoxylate shunt, for complete oxidation to carbon dioxide or be converted to acetate via the action of phosphate acetyl transferase (Snov_4211) and acetate kinase (Snov_2209) (Figure 1A, Table S2).

\section{COMPOSITION OF THE RESPIRATORY CHAIN}

Following the complete oxidation of acetyl-CoA to carbon dioxide the resulting $\mathrm{NADH} / \mathrm{FADH}_{2}$ can enter the respiratory chain (Table 1 and Table S2) which is composed of a complete complex I (NADH: ubiquinol oxidoreductase, EC 1.6.5.3, Snov_1849Snov_1864), a succinate dehydrogenase (complex II, EC 1.3.5.1, Snov_3317-Snov_3320), and a cytochrome $b c_{1}$ complex (complex III, EC 1.10.2.2, Snov_2477-Snov_2479) (Figure 1C, Table S2). In addition there are two more loci (Snov_2406-Snov_2408 and Snov_3849-Snov_3850) encoding three or two proteins, respectively, annotated as subunits of complex I, as well as two putative formate dehydrogenases (FDH) (Snov_3504-Snov_3507, put FDH-F type; Snov_3851-Snov_3852, put FDH-O/N type), an arsenite oxidase (Snov_1288-Snov_1289), and a putative LldD type lactate dehydrogenase (Snov_0680) that can also feed electrons into the respiratory chain.

This large number of dehydrogenase enzymes that can feed electrons into the respiratory chain is linked to an array of terminal reductases that can mediate both aerobic and anaerobic respiration (Figure 1C). The final step in respiration can use at least six types of cytochrome or quinol oxidases, including two $a_{3}$ type oxidases (Snov_0584-Snov_0589 and Snov_4240Snov_4243). The second of these two enzymes, Snov_4240 has similarity to both Cox1 ( $\mathrm{aa}_{3}$ type oxidase) and $\mathrm{CyoB}$ oxidases with the similarity to the Coxl enzymes being slightly higher. Despite this the current annotation classifies the enzyme as a CyoB-type oxidase. Another gene locus (Snov_1015-Snov_1019) also encodes proteins related to the heme $\mathrm{Cu}$ oxidases (cyoBtype quinol oxidases) and here one protein (Snov_1016) is a fusion of the subunit I and subunit III cytochrome oxidase domains. This type of cytochrome oxidase appears to be conserved in a variety of $\alpha-, \beta$-, and $\gamma$-Proteobacteria as well as some Planktomycetes. A $c b b_{3}$-type oxidase with high oxygen affinity (Snov_4464-Snov_4468) is present as well as two bd-type quinol oxidases (Snov_0619-Snov_0620 and Snov_3535-3536) which are also known for their high affinity to oxygen. Complementing the aerobic respiration are several terminal reductases known to be involved in anaerobic respiration such as nitrate reductase (Nap-type, Snov_1159-Snov_1162, EC 1.7.99.4), a cytochrome $c$ dependent nitrite reductase (Snov_1147; EC 1.7.2.1), and a nitric oxide reductase (Snov_1155; EC 1.7.2.4) (Figure 1C). There are also several uncharacterized enzymes of the DMSO reductase 


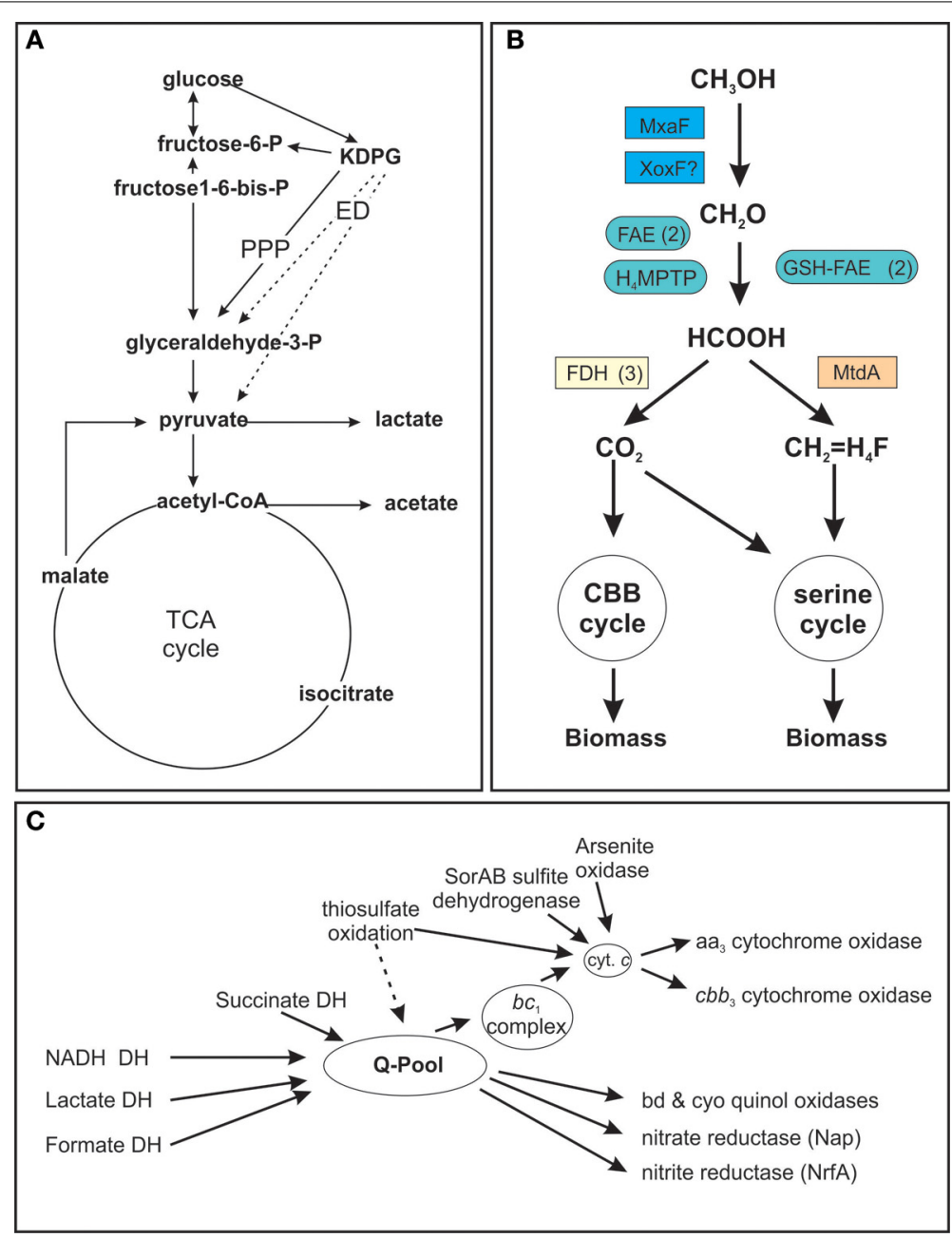

FIGURE 1 | Schematic representation of $S$. novella metabolic pathways. (A) Glucose catabolism and TCA cycle (B) Methanol degradation (C) Respiratory chain components. (A) Dashed arrows denote reactions of the Entner Doudoroff (ED) pathway, PPP, Pentose Phosphate Pathway; DH, dehydrogenase, KDPG, 2-keto-3-deoxy-6-phosphocluconate. (B): H4MPTP, methylene tetrahydromethanopterin pathway; MtdA, methylene tetrahydromethanopterin dehydrogenase; FAE, formaldehyde activating enzyme; GSH-FAE, Glutathione dependent formaldehyde activating enzyme; FDH, formate dehydrogenase. (C) Q-pool, quinone pool. Gene numbers for all components or the different pathways are listed in the supplementary tables. Carbon metabolism_Table S2; Respiratory chain_Table S3; methanol metabolism-Table S4. enzyme family encoded in the S. novella genome (Kappler and Nouwens, 2013) which may also be linked to the respiratory chain.

\section{METABOLIC PATHWAYS AND GENES INVOLVED IN C1 METABOLISM IN S. novella}

While it has been known for over 30 years that S.novella can use methanol as a growth substrate, the relevant pathways and enzymes had never been studied. Our analyses showed that the ability of $S$. novella to oxidize methanol appears to be based on a combination of pathways and enzymes similar to those of a model methylotroph, Methylobacterium extorquens (reviewed in Chistoserdova, 2011). A full operon encoding an MxaF type methanol dehydrogenase (Snov_4185-Snov_4199, mxaBxHFJGARSACKLDE) was identified as well as a $x o x F$ gene locus (Snov_1035-Snov_1038) encoding a putative methanol dehydrogenase-homolog (Figure 1B). While XoxF has been suggested to be involved in methanol oxidation in some bacteria, the exact function of this enzyme is still being investigated (Chistoserdova, 2011). Two copies each of genes encoding glutathione dependent (Snov_1125, Snov_1350) and independent putative formaldehyde-activating enzymes (FAEs) (Snov_0740, Snov_1050) (Vorholt et al., 2000; Goenrich et al., 2002) are present in the $S$. novella genome. These enzymes target the formaldehyde produced by the methanol dehydrogenases for further conversion via the tetrahydromethanopterin $\left(\mathrm{TH}_{4} \mathrm{MP}\right)$ pathway (Chistoserdova et al., 2009; Chistoserdova, 2011). For the assimilation of carbon units into cell biomass $S$. novella contains a complete serine pathway, as well as a tetrahydrofolate $\left(\mathrm{TH}_{4} \mathrm{~F}\right)$ and a tetrahydromethanopterin $\left(\mathrm{TH}_{4} \mathrm{MP}\right)$ pathway (Tables 1, 3 and Table S2; Figure 1B). A complete Calvin Benson Bassham (CBB)-cycle for carbon dioxide fixation is also present (Table S2). 
Table 1 | Presence of proteins involved in carbon dioxide fixation and respiration in S. novella cell extracts from chemolithoautotrophic, methylotrophic, heterotrophic, and mixotrophic growth conditions.

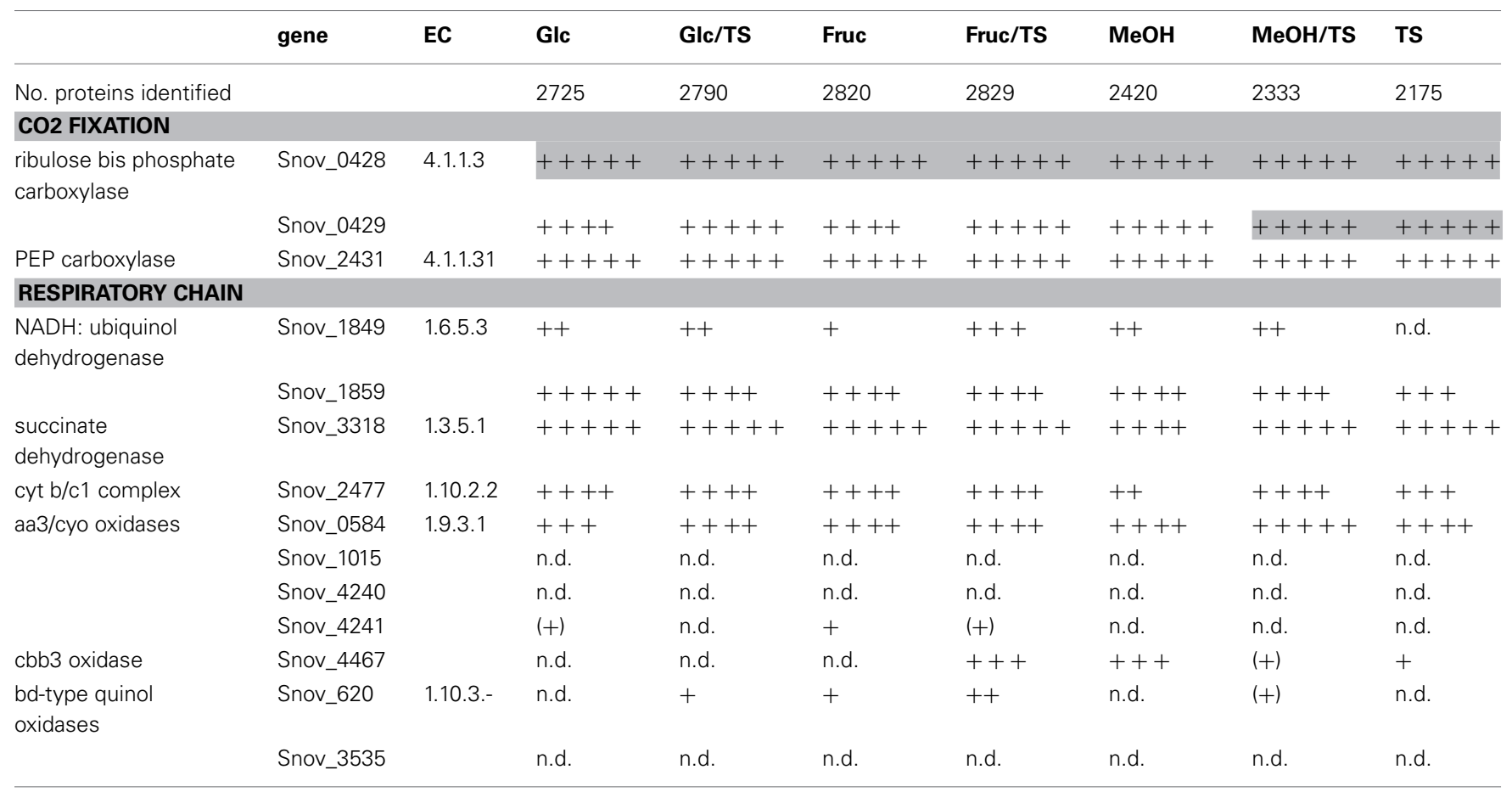

+ , indicate expression levels, with the number of crosses indicating the band in which the protein was detected;,+++++ top $10 \%$ of proteins;,$++++ 10-30 \%$;

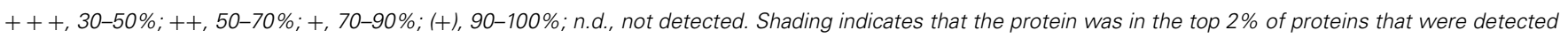
in the sample.

\section{DISSIMILATORY SULFUR OXIDATION PATHWAYS}

Although the ability of $S$. novella to grow as a sulfur chemolithoautotroph was recognized at the time of its isolation (Starkey, 1935), details of the enzymes and pathways involved have only been elucidated recently. A gene region encoding the four core enzymes of a Sox-type sulfur oxidation pathway had been identified previously (Kappler et al., 2001, 2004) and analysis of the genome showed that this gene cluster (Snov_0978-Snov_0965) is more extensive than previously recognized. The full gene cluster contains 15 genes, soxT(R)S-soxVW-soxAX-soxYZBCDorf1Forf2, organized in at least four separate transcriptional units as indicated (Figure 2A).

Interestingly, in the current genome annotation the soxR gene that encodes a regulator of thiosulfate oxidation is marked as a pseudogene, possibly due to an N-terminal truncation of the encoded protein caused by a frameshift mutation at $\sim \mathrm{bp} 58-62$ (sequence: CCCC) in the soxR gene that leads to a loss of 26 aa at the N-terminus of the protein (assuming translation of the truncated protein would start at the closest ATG codon). Analysis of the genome also revealed the presence of a second, smaller sox gene cluster ( $\operatorname{sox} X_{2} Y_{2} Z_{2} A_{2} F_{2}$, genes Snov_1982-1977) which encodes duplicate copies of two of the core components of the Sox system (SoxAX, SoxYZ; the SoxB and SoxCD proteins are missing) (Figure 2A). This operon also contains genes encoding a molybdenum enzyme of the Xanthine Oxidase family (Snov_1975/Snov_1976) that was identified in an analysis of the molybdoproteome of S. novella (Kappler and Nouwens, 2013).

We also analyzed the presence of other enzymes capable of oxidizing a variety of reduced sulfur compounds. A Sox complex independent sulfite oxidizing enzyme, SorAB, had already been identified previously (Kappler et al., 2000) and the enzyme itself has been extensively characterized (Kappler and Bailey, 2005; Kappler et al., 2006, 2012; Rapson et al., 2008; Bailey et al., 2009; Emesh et al., 2009). No evidence was found for the presence of Sox complex independent sulfide oxidizing enzymes such as flavocytochrome $c$ and sulfide:quinone reductase. Similarly, despite early observations of a GSH-dependent sulfur oxygenase activity in S. novella (Charles and Suzuki, 1966a), no homologs of bacterial sulfur oxygenases were identified using the Acidithiobacillus caldus enzyme (acc no ZP_0529337) as the search model.

\section{ADAPTATION OF S. novella METABOLISM TO THE PRESENCE OF VARIOUS CARBON AND SULFUR SOURCES}

In order to investigate the importance of the enzymes and pathways identified above for metabolic adaptation of $S$. novella we analyzed protein and gene expression in S. novella cultures grown under heterotrophic (glucose, fructose), methylotrophic (methanol), and sulfur chemolithoautotrophic (thiosulfate/carbon dioxide) conditions as well as under mixotrophic conditions where thiosulfate was combined with either a substrate for heterotrophic (glucose or fructose) or methylotrophic growth (methanol). 


\section{CARBON METABOLISM}

As might be expected, enzymes belonging to key pathways of central carbon metabolism were detected under all conditions tested using shotgun proteomics (Table S2). These included the

A S. novella sox cluster 1 (Snov_0972 gene region)

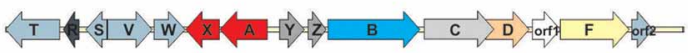

S. novella sox cluster 2 (Snov_1975 gene region)

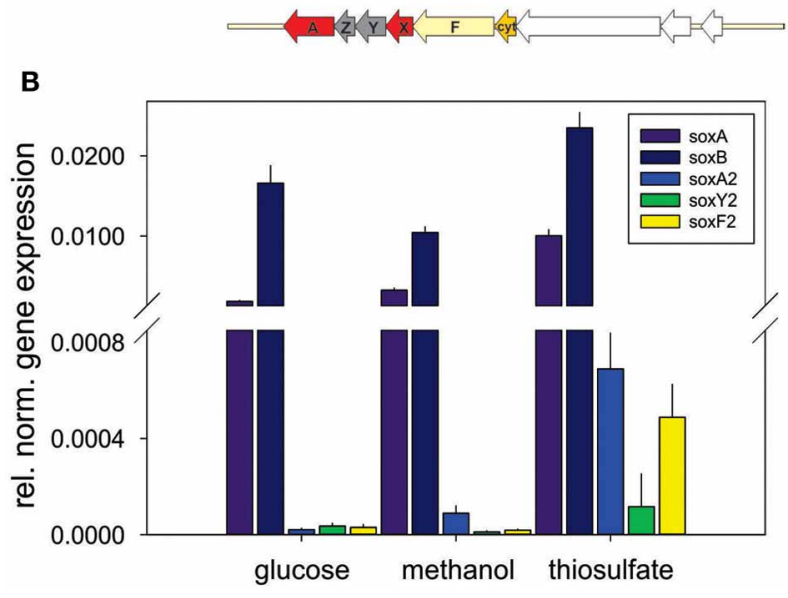

FIGURE 2 | Genes involved in dissimilatory sulfur oxidation in $\boldsymbol{S}$. novella. (A) Schematic representation of the two sox gene clusters encoded in the $S$. novella genome. sox $A X$, red; sox $Y Z$, dark gray; soxB, light blue; soxC, light gray; soxD, orange; soxF, yellow; accessory genes (e.g., soxV,W,S etc.), blue gray; sox $R$, dark blue gray; orf1 membrane anchor protein (main sox cluster) and Xanthine Oxidase family Mo enzyme (second sox cluster), no fill. (B) Expression of sox genes in $S$. novella cultures grown in the presence of glucose, methanol, or thiosulfate/ $\mathrm{CO}_{2}$. Error bars represent the Standard Deviation of the mean, gene expression was normalized relative to the expression of the 16S RNA gene. A number " 2 " added to the gene name denotes that this gene is present in the second sox gene cluster. pentose phosphate and glycolysis pathways (although the latter likely is used for gluconeogenesis rather than glucose oxidation), the pyruvate dehydrogenase complex and all enzymes of the TCA cycle (Table S2). Enzymes of the glyoxylate shunt were also always expressed but its key enzyme, isocitrate lyase (ICL), appeared to undergo some regulation in response to changing carbon sources, for example in the presence of glucose and during growth on thiosulfate ICL was not detected, and during growth on fructose ICL was in the bottom $5 \%$ of proteins detected (Table S2).

Phosphoenolpyruvate carboxylase, an enzyme catalyzing an anaplerotic reaction leading to $\mathrm{CO}_{2}$ fixation, was always present at high levels (within the top 10\% of proteins detected) (Table 1), and in addition to the PPP which appeared to be the main pathway for the degradation of sugars, enzymes specific to the ED pathway were also detected, however, one of the key enzymes, 2-dehydro-3 deoxy-gluconate aldolase was not detected during growth on fructose, methanol or thiosulfate, suggesting that this pathway is not used during growth on these substrates (Table S2).

Respiratory chain complexes also showed very consistent patterns of expression with ATP synthase (Snov_4429-4433), complexes I (Snov_1852-Snov1864 gene region), II (succinate dehydrogenase, Snov_3317-Snov_3320) and the $b c_{1}$ complex being present under all conditions tested (Table 1 and Table S3). Considerable variation in expression was, however, present for the six terminal oxidase complexes encoded in the $S$. novella genome. Of the $a_{3} /$ cyo type oxidases only the aa 3 -type enzyme encoded by the Snov_0584 gene region was detected at appreciable levels using shotgun proteomics. The enzymes encoded in the Snov_1015 and Snov_4241 gene regions were either completely absent or only present at low levels under specific conditions (Glc and Fruc, bottom 10\% and 15\% of proteins detected). The core subunits of the $c b b_{3}$ terminal oxidase were only present when thiosulfate, methanol, methanol/thiosulfate or fructose/thiosulfate were used as growth substrates, while of the two $b d$-type quinol oxidases only the enzyme encoded by the Snov_0620 gene region was detected, mostly in samples from mixotrophic growth (Table 1). These results mostly match the qPCR data generated from cDNA of cultures grown on glucose, methanol or thiosulfate medium (Figure 3), with the exception of

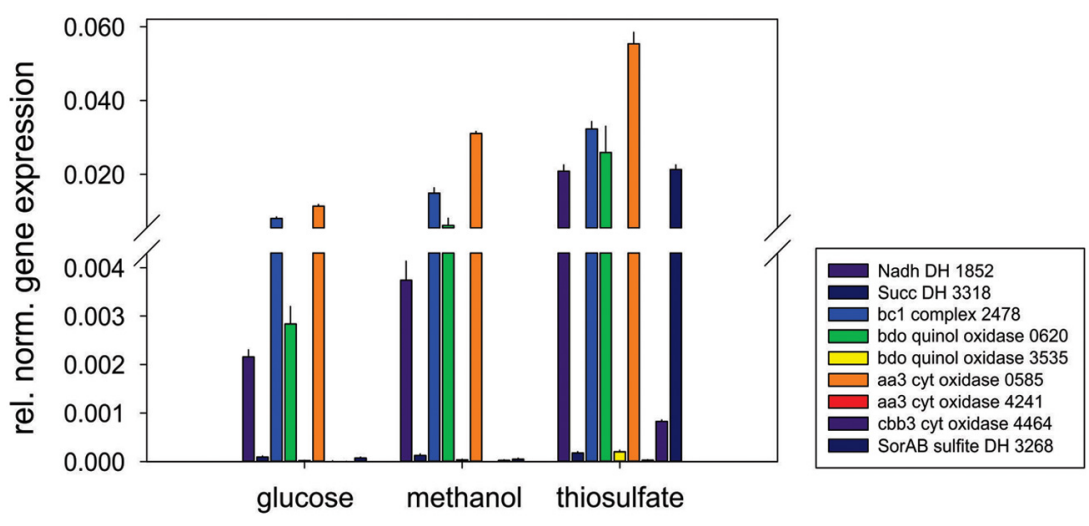

FIGURE 3 | Expression of respiratory chain genes in $\boldsymbol{S}$. novella cultures grown under hetero-trophic, methylotrophic, or sulfur chemolithoautotrophic conditions. Error bars represent the Standard Deviation of the mean, gene expression was normalized relative to the expression of the $16 \mathrm{~S}$ RNA gene. 
expression of the Snov_0620 encoded bd oxidase which showed comparatively high expression levels under the three conditions tested, while only low amounts of the corresponding proteins were detected. A possible explanation for the lower levels of detection for peptides could be the association of the respiratory chain complexes with the cell membrane.

\section{DISSIMILATORY SULFUR METABOLISM}

Monitoring of the expression of enzymes for chemolithotrophic growth using sulfur compounds revealed that the previously discovered sox operon (Snov_0978-Snov_0968) that encodes a complete Sox-type thiosulfate oxidation enzyme complex is the main operon involved in chemolithotrophic sulfur oxidation in S.novella (Table 2, Figure 2). All relevant proteins were detected in all proteome samples analyzed, and several core proteins of the enzyme complex (SoxB, SoxA, and Sox C) were always among the top 100 protein detected in the samples (Table 2). Levels of the flavocytochrome $c$-like SoxF protein were lowest relative to the other complex components (within the top $40-60 \%$ of proteins). We also detected peptides for a protein encoding a putative membrane anchor protein (DUF1791 type protein), Snov_0966 or Orf1, which had previously been suggested to act as a potential membrane anchor for the S. novella Sox complex (Kappler et al., 2004) which had been postulated by early biochemical studies (Aleem, 1965; Charles and Suzuki, 1966a; Kappler et al., 2004). Using qRT-PCR we also found evidence for the functionality of the $\operatorname{soxR}$ "pseudogene" for which expression was detected under all three conditions tested, with the highest levels detected in the presence of thiosulfate (Figure S1).

In contrast the SoxAX and SoxYZ proteins encoded by the second sox gene cluster (Snov_1982-Snov_1979) were not detected, although one subunit of the SoxF-like flavocytochrome $c$ protein (Snov_1977-Snov_1978) was present at low levels ( bottom $20 \%$ of protein detected) throughout except following growth on glucose. A SoxZ-like protein encoded by a single gene (Snov_1060) was detected among the top $25-50 \%$ of proteins throughout, but the function of this protein is unclear as it is encoded by a gene that does not appear to form an operon with any of the adjacent genes, and none of these encode a SoxY-like protein.

These results are in agreement with qRT-PCR experiments that also showed high expression for genes encoded in the main sox cluster, and very low expression levels for proteins from the second sox gene cluster (Figure 2B). Both gene expression and proteomic data clearly showed that the SorAB sulfite dehydrogenase (Snov_3268/3269) is induced by the presence of thiosulfate in the growth medium regardless of the carbon source present as already reported in Kappler and Nouwens (2013).

\section{METABOLISM OF C1-COMPOUNDS}

$S$. novella has been classified as a facultative methylotroph since the discovery of its ability to oxidize methanol, however, similar to what was observed for sulfur chemolithotrophic growth, the MxaF methanol dehydrogenase was one of the five most abundant proteins detected under all conditions tested except when

Table 2 | Presence of proteins involved in sulfur chemolithotrophy in S. novella cell extracts from chemolithoautotrophic, methylotrophic, heterotrophic, and mixotrophic growth conditions.

\begin{tabular}{|c|c|c|c|c|c|c|c|c|}
\hline & Gene number & Glc & Glc/TS & Fruc & Fruc/TS & $\mathrm{MeOH}$ & MeOH/TS & TS \\
\hline $\begin{array}{l}\text { Total no of proteins } \\
\text { detected in cell } \\
\text { extracts }\end{array}$ & & 2725 & 2790 & 2820 & 2829 & 2420 & 2333 & 2175 \\
\hline \multicolumn{9}{|l|}{ MAIN Sox CLUSTER } \\
\hline SoxF & Snov_965 & ++ & ++ & +++ & +++ & +++ & +++ & ++ \\
\hline orf1 & Snov_966 & +++++ & +++++ & +++++ & +++++ & ++++ & +++++ & $+++t$ \\
\hline SoxD & Snov_967 & +++++ & ++++ & +++++ & ++++ & ++++ & +++++ & +++++ \\
\hline SoxC & Snov_968 & ++++ & +++++ & +++++ & +++++ & ++++ & +++++ & ++++ \\
\hline SoxB & Snov_969 & ++++ & ++++ & +++++ & +++++ & ++++ & +++++ & ++++ \\
\hline SoxZ & Snov_970 & ++++ & ++++ & +++ & ++++ & ++++ & ++++ & ++++ \\
\hline SoxY & Snov_971 & +++++ & ++++ & ++++ & ++++ & ++++ & ++++ & ++++ \\
\hline $\operatorname{SoxA}$ & Snov_972 & ++++ & +++++ & ++++ & ++++ & ++++ & ++++ & ++++ \\
\hline SoxX & Snov_973 & +++++ & +++++ & +++++ & ++++ & +++++ & +++++ & +++++ \\
\hline \multicolumn{9}{|c|}{ SECOND Sox CLUSTER } \\
\hline Flavocyt Su B & Snov_1977 & n.d. & n.d. & n.d. & n.d. & n.d. & n.d. & n.d. \\
\hline Flavocyt Su A & Snov_1978 & n.d. & $(+)$ & + & $(+)$ & + & + & + \\
\hline Sox $\times 2$ & Snov_1979 & n.d. & n.d. & n.d. & n.d. & n.d. & n.d. & n.d. \\
\hline SoxY2 & Snov_1980 & n.d. & n.d. & n.d. & n.d. & n.d. & n.d. & n.d. \\
\hline SoxZ2 & Snov_1981 & n.d. & n.d. & n.d. & n.d. & n.d. & $(+)$ & n.d. \\
\hline SoxA2 & Snov_1982 & n.d. & n.d. & n.d. & n.d. & n.d. & n.d. & n.d. \\
\hline orphan 'SoxZ' & Snov_1060 & ++++ & +++ & +++ & +++ & +++ & +++ & ++++ \\
\hline
\end{tabular}

+ , indicate expression levels, with the number of crosses indicating the band in which the protein was detected;,+++++ top $10 \%$ of proteins;,$++++ 10-30 \%$;

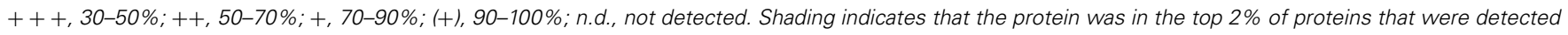
in the sample. 
fructose was included in the medium where $\mathrm{MxaF}$ was among the top 20 proteins detected. This clearly indicates that together with sulfur chemolithotrophy, methylotrophy is another key growth mode for $S$. novella and it is also similar to what was found in M. extorquens (Bosch et al., 2008). While all proteins of the $m x a$ operon were detected in all samples, a slight increase in protein abundance was observed when methanol was the growth substrate (Table 3 and Table S4). The second possible methanol dehydrogenase, the XoxFGJ protein, was also detected in all samples. XoxF was usually found in the top 100-200 proteins detected, except when methanol or thiosulfate were the growth substrates when XoxF was ranked approx. 70 out of over 2000 detected proteins. This indicates a role for this protein in methylotrophic and possibly also sulfur chemolithotrophic growth.

Other enzymes involved in methylotrophy such as the two glutathione dependent FAEs were either expressed at low levels ( bottom $30 \%$-bottom $5 \%$ of proteins detected) or not at all, while of the two GSH - independent FAEs the Snov_0740 enzyme was always among the top $40-50 \%$ of protein detected and showed no obvious substrate dependent regulation. In contrast, the Snov_1050 encoded FAE was among the top 10\% of proteins detected, and in the presence of methanol and/or thiosulfate the relative abundance of the protein increased (top 3\% of proteins detected) clearly linking this enzyme to methylo- and chemolithotrophic growth (Table 3 and Table S4). The qRT-PCR data also showed an increase in Snov_1050 transcripts in the presence of methanol and thiosulfate (Figure 4).

A similar observation was made for the FDHs where the Snov_3851 encoded FDH was clearly induced in the presence of methanol (protein abundance increased from the top 40-50\% to the top 5\% of proteins), and the Snov_3504 FDH showed increased abundance in thiosulfate and methanol/thiosulfate containing samples. Again, the overall patterns observed for the gene expression data matched the shotgun proteomic data (Figure 4,
Table 3). For further assimilation of the $\mathrm{C} 1$ units the serine pathway, the methylene tetrahydromethanopterin pathway and the enzymes of the Calvin cycles were expressed in S. novella under all conditions (Figure 3, Table 1 and Table S2), with the abundance of enzymes of the latter pathway increasing in the presence of methanol, thiosulfate or a combination of the two.

\section{DISCUSSION}

Although several proteomic studies of soil bacteria, their interactions with plants and their responses to a variety of environmental stresses (e.g., heavy metals) have been carried out (Hansmeier et al., 2006; Cheng et al., 2010; Ray et al., 2013; Van Dijl and Hecker, 2013), the interplay between different growth modes associated with carbon and sulfur metabolism have not previously been investigated in a free living soil bacterium despite their significance for global element cycles and the speciation of carbon and sulfur compounds in the environment.

The data presented above clearly demonstrate that in $S$. novella, the pathways associated with sulfur chemolitho- and methylotrophic growth modes are constantly expressed at high levels regardless of the carbon sources present and independent of auto-, mixo- or heterotrophic growth conditions. Some form of substrate dependent regulation appeared to occur for some pathway components, but in general key enzymes were found to be highly abundant. This then indicates that both methylotrophy and sulfur chemolithotrophy are key growth modes for $S$. novella which in turn raises the question whether $S$. novella should be classified as a facultative methylo- and chemolithotroph. It also appears that in the presence of methanol and thiosulfate $S$. novella does employ a mixotrophic growth strategy as cultures grown in the presence of both substrates reached culture densities that were at least twice as high as the maximum values obtained after growth on thiosulfate, indicating that methanol must have been utilized by the bacteria to increase cell growth, and cultures grown

Table 3 | Presence of proteins involved in methylotrophy S. novella in cell extracts from chemolithoautotrophic, methylotrophic, heterotrophic and mixotrophic growth conditions.

\begin{tabular}{|c|c|c|c|c|c|c|c|c|}
\hline & Gene number & Glc & GIc/TS & Fruc & Fruc/TS & $\mathrm{MeOH}$ & $\mathrm{MeOH} / \mathrm{TS}$ & TS \\
\hline No of proteins detected & & 2725 & 2790 & 2820 & 2829 & 2420 & 2333 & 2175 \\
\hline \multicolumn{9}{|c|}{ METHANOL DEHYDROGENASES } \\
\hline XoxF & Snov_1035 & ++++ & ++++ & ++++ & ++++ & ++++ & ++++ & ++++ \\
\hline \multicolumn{9}{|c|}{ FORMALDEHYDE ACT. ENZYMES } \\
\hline \multicolumn{9}{|c|}{ GSH DEP. FORMALDEHYDE ACT. ENZYMES } \\
\hline GFA1 & Snov_1125 & ++ & + & $(+)$ & + & $(+)$ & ++ & n.d \\
\hline GFA2 & Snov_1340 & ++ & ++ & ++ & + & n.d & n.d & + \\
\hline \multicolumn{9}{|c|}{ FORMATE DEHYDROGENASES } \\
\hline FDH1 & Snov_3504 & +++ & ++++ & +++++ & ++++ & +++ & ++++ & ++++ \\
\hline
\end{tabular}

,+ indicate expression levels, with the number of crosses indicating the band in which the protein was detected;,+++++ top $10 \%$ of proteins;,$++++ 10-30 \%$; ,$+++ 30-50 \% ;++, 50-70 \% ;+, 70-90 \% ;(+), 90-100 \% ; n . d .$, not detected. Shading indicates that the protein was in the top $2 \%$ of proteins that were detected in the sample. 


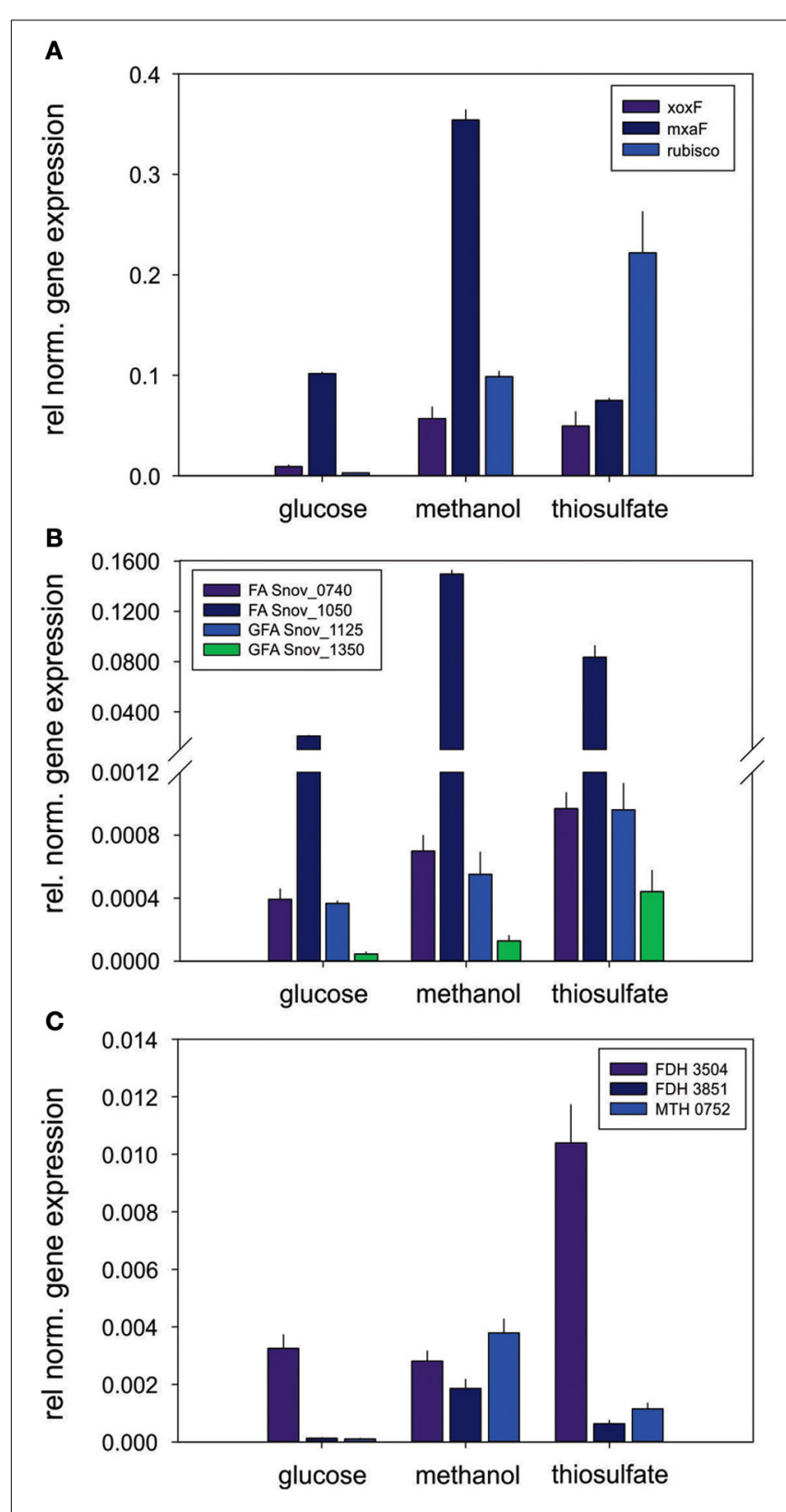

FIGURE 4 | Expression of genes involved in methylotrophy in $\boldsymbol{S}$. novella. (A) Methanol oxidation and carbon dioxide fixation (Calvin cycle), (B) Formaldehyde activating enzymes, (C) Formate dehydrogenases. Error bars represent the Standard Deviation of the mean, gene expression was normalized relative to the expression of the 16S RNA gene.

on methanol and thiosulfate showed a strong thiosulfate dependent respiratory activity in experiments using an oxygen electrode (Kappler, unpublished).

Enzymes for various pathways allowing $\mathrm{CO}_{2}$ fixation were also expressed under all growth conditions tested, and this included the anaplerotic reaction mediated by PEP carboxylase as well as enzymes of the Calvin and serine cycle, which suggests a role for $\mathrm{CO}_{2}$ fixation processes in balancing metabolic fluxes and possibly also redox states. Especially the enzymes of the Calvin cycle were highly abundant in S. novella under all conditions tested, indicating that it might be the major pathway for carbon dioxide fixation.

Our results are in contrast to a study by Lejohn et al. (1967) who reported catabolite repression of thiosulfate oxidation in the presence of glucose, lactate, glycerol, ribose, and pyruvate, while several amino acids, including glutamate were reported not to cause any inhibition. The results of our work agree, however, with data of a later study (Perez and Matin, 1980) which found that glucose and thiosulfate were oxidized concurrently to carbon dioxide and sulfate by $S$. novella independent of the relative concentrations of glucose and thiosulfate. As both of these studies as well as our work used the same strain of $S$. novella $\left(\mathrm{DSMZ506} 6^{T}=\right.$ ATCC $8093^{\mathrm{T}}$ ) and very similar mineral media for the cultivation of the bacteria it is unclear what caused the observed difference in substrate utilization. Another study that investigated S. novella substrate utilization under nutrient limiting conditions in continuous culture (Leefeldt and Matin, 1980) also found a concurrent utilization of substrates.

In this work, proteins involved in central carbon metabolism pathways of $S$. novella were detected under all growth conditions tested, and our data thus agree with enzymatic studies of $S$. novella physiology that indicated that a complete TCA and glyoxylate cycle were present under both auto- and heterotrophic growth conditions (Charles, 1971). The presence of PEP carboxylase and RubisCO under all growth conditions tested also agrees with data from an earlier study (McCarthy and Charles, 1974), although neither the proteomic nor the qRT-PCR data detected the regulatory pattern observed by McCarthy and Charles (1974). McCarthy and Charles (1974) reported that autotrophically grown cells had much higher levels of RubisCO activity and lower levels of PEP carboxylase activity relative to heterotrophically grown cells while our data clearly indicate nearly invariant, high expression levels for both enzymes in the top $10 \%$ of proteins detected in each sample. A possible explanation for this difference could be that e.g., the enzymatic activity of RubisCO can be modulated by protein modifications and intracellular inhibitors (Jouanneau and Tabita, 1987; Wang and Tabita, 1992; Tabita, 1999), and thus the amount of protein present in the cell would not necessarily reflect the level of enzyme activity observed.

Another interesting observation is that while there are two gene clusters encoding components of a Sox-type thiosulfate oxidation pathway, only the gene cluster encoding the complete Sox complex was expressed at significant levels. This suggests that in S.novella the additional components of the Sox multienzyme system encoded in the second sox gene cluster have no functional significance as had been suggested e.g., for modulating substrate specificities through the use of isoenzymes of the SoxAX cytochromes (Frigaard and Dahl, 2008; Gregersen et al., 2011; Kappler and Maher, 2013). As at present not much is known about the roles of duplicate sox genes for microbial physiology the results presented here should be followed up by additional work on other bacteria that contain gene loci encoding multiple copies of sox genes to confirm the lack of a functional role. It is also possible that the second sox gene cluster in $S$. novella is important under growth conditions other than those tested here.

Of additional interest is the putative SoxR regulator encoded in the main sox gene cluster. Although classified in the genome 
annotation as a pseudogene, qRT-PCR (Figure S1) clearly indicated that the gene is functional and would presumably give rise to a functional SoxR protein. Given that regulation of expression of the main S. novella sox gene cluster happens at a very high level of expression it will be interesting to determine possible functional differences between the truncated SoxR regulator from S. novella and the characterized, full length SoxR regulators from $P$. pantotrophus and Pseudoaminobacter salicylatoxydans (Rother et al., 2005; Mandal et al., 2007).

Redundancy of genes encoding various elements of the degradation pathway also characterizes the methylotrophy pathways in S. novella (Table 3 and Table S4, Figure 1), and based on our data it was possible to clearly assign a role in methylotrophy to some of the redundant systems, such as the MxaF methanol dehydrogenase which appears to be the main methanol oxidizing enzyme, the Snov_1050 encoded FAE and the Snov_3851 encoded FDHs which were clearly methanol inducible.

Overall our results indicate that $S$. novella employs a mixotrophic growth strategy, in which several pathways for "specialized" types of metabolism such as the utilization of C1compounds and dissimilatory energy generation from sulfur compounds are always expressed at high levels. This is in contrast to studies on other bacteria such as Paracoccus pantotrophus where thiosulfate oxidation was induced by the presence of thiosulfate (Robertson and Kuenen, 1983; Chandra and Friedrich, 1986; Rother et al., 2005) but is reminiscent of what has been reported for $M$. extorquens, where methanol and succinate were found to be co-metabolized and enzymes involved in methylotrophy were always expressed at high levels (Bosch et al., 2008; Peyraud et al., 2012).

It would then appear that the classification of $S$. novella as a facultative sulfur chemolithoauto- and methylotroph (Starkey, 1935; Kelly et al., 2000) does not accurately reflect the growth strategy employed by this bacterium. At this stage we can only speculate on the possible advantages inherent in this, but it is obvious that in such a bacterium production or sequestration/degradation of greenhouse active substances such as methanol or carbon dioxide would depend on the exact growth conditions encountered and the net contribution of $S$. novella to these processes might change very quickly in response to a changing environment, and soils are known to undergo significant fluctuations in many environmental parameters including oxygen and nutrient availability. This has direct implications for the modeling of microbially mediated climate relevant processes in soils, and also raises the question whether bacteria

\section{REFERENCES}

Aleem, M. I. H. (1965). Thiosulfate oxidation and electron transport in Thiobacillus novellus. J. Bacteriol. 90, 95-101.

Altschul, S. F., Madden, T. L., Schaffer, A. A., Zhang, J., Zhang, Z., Miller, W., et al. (1997). Gapped BLAST and PSI-BLAST: a new generation of protein database search programs. Nucleic Acids Res. 25, 3389-3402. doi: 10.1093/nar/25.17. 3389
Ausubel, F. (1995). Short Protocols in Molecular Biology: a Compendium of Methods from Current Protocols in Molecular Biology. Hoboken, NJ: John Wiley and Sons.

Bailey, S., Rapson, T., Winters-Johnson, K., Astashkin, A. V., Enemark, J. H., and Kappler, U. (2009). Molecular basis for enzymatic sulfite oxidation - how three conserved active site residues shape enzyme activity. J. Biol. Chem. 284, 2053-2063. doi: 10.1074/jbc.M807718200

related to $S$. novella might use a similar combination of growth modes.

S. novella is a member of the family Xanthobacteraceae and within this family it is most closely related to Ancylobacter sp. which have been isolated from soils and waterbodies and are known methylotrophs (Kelly et al., 2000; Xin et al., 2006). No complete genome sequences for Ancylobacter sp. are available at present, and the description of most known Ancylobacter sp. does not mention whether their ability to oxidize thiosulfate was tested and this trait is not mentioned in the original species description or Bergey's Manual of Systematic Bacteriology (Larkin et al., 1977; Raj, 1989; Garrity et al., 2005; Xin et al., 2006). However, in 1998 several isolates of thiosulfate oxidizing soil bacteria were identified as Ancylobacter sp. (Stubner et al., 1998) and a recent description of a new Ancylobacter species, A. dichloromethanicus mentions growth as a facultative thiosulfate oxidizer as a trait of the species (Firsova et al., 2009). Similarly, Xanthobacter species including $X$. autotrophicus are known to be able to derive energy from thiosulfate oxidation, but the trait is not part of the species description, while the utilization of methanol as a growth substrate is recognized as a trait of the species (Padden et al., 1998; Stubner et al., 1998; Garrity et al., 2005).

It would thus appear that the organisms of the family Xanthobacteraceae not only share similar habitats (soils, plant root systems, and freshwater, including sediments) but also share many key metabolic traits, and it will be interesting to investigate whether representatives of other species within the family share any of the regulatory features uncovered here for Starkeya novella. Data of this type will be of prime importance for understanding mineralization processes in soil environment as well as the impact of these processes on climate relevant processes.

\section{ACKNOWLEDGMENTS}

This work was supported by a grant and fellowship by the Australian Research council (DP0878525 and Australian Research Fellowship) to Ulrike Kappler.

\section{SUPPLEMENTARY MATERIAL}

The Supplementary Material for this article can be found online at: http://www.frontiersin.org/journal/10.3389/fmicb. 2013.00304/abstract

Figure S1 | Expression of the $S$. novella soxR "pseudogene" in cultures grown with glucose, methanol of thiosulfate as energy sources. Error bars represent the standard deviation of the mean. Expression data were normalized relative to the expression of the $16 \mathrm{~S}$ gene.

Bosch, G., Skovran, E., Xia, Q., Wang, T., Taub, F., Miller, J. A., et al. (2008). Comprehensive proteomics of Methylobacterium extorquens AM1 metabolism under single carbon and nonmethylotrophic conditions. Proteomics 8, 3494-3505. doi: 10.1002/pmic. 200800152

Caspi, R., Altman, T., Dreher, K., Fulcher, C. A., Subhraveti, P., Keseler, I. M., et al. (2012). The MetaCyc database of metabolic pathways and enzymes and the BioCyc collection of pathway/genome databases. Nucleic Acids Res. 40, D742-D753. doi: 10. 1093/nar/gkr1014

Chandra, T. S., and Friedrich, C. G. (1986). Tn5-induced mutations affecting sulfur-oxidizing ability (Sox) of Thiosphaera pantotropha. J. Bacteriol. 166, 446-452.

Chandra, T. S., and Shethna, Y. I. (1977). Oxalate, formate, formamide, and methanol metabolism 
in Thiobacillus novellus. J. Bacteriol. 131, 389-398.

Charles, A. M. (1971). Effect of growth substrate on enzymes of the citric and glyoxylic acid cycles in Thiobacillus novellus. Can. J. Microbiol. 17, 617-624. doi: 10.1139/m71-101

Charles, A. M., and Suzuki, I. (1966a). Mechanism of thiosulfate oxidation by Thiobacillus novellus. Biochim. Biophys. Acta 128, 510-521. doi: 10.1016/0926-6593(66)90012-9

Charles, A. M., and Suzuki, I. (1966b). Purification and properties of sulfite:cytochrome $c$ oxidoreductase from Thiobacillus novellus. Biochim. Biophys. Acta 128, 522-534. doi: 10.1016/0926-6593(66)90013-0

Cheng, Z., McConkey, B. J., and Glick, B. R. (2010). Proteomic studies of plant-bacterial interactions. Soil Biol. Biochem. 42, 1673-1684. doi: 10.1016/j.soilbio.2010.05.033

Chistoserdova, L. (2011). Modularity of methylotrophy, revisited. Env. Microbiol. 13, 2603-2622. doi: 10.1111/j.1462-2920.2011.02464.x

Chistoserdova, L., Kalyuzhnaya, M. G., and Lidstrom, M. E. (2009). The expanding world of methylotrophic metabolism. Annu. Rev. Microbiol. 63, 477-499. doi: 10.1146/annurev. micro.091208.073600

Eiler, A. (2006). Evidence for the ubiquity of mixotrophic bacteria in the upper ocean: Implications and consequences. Appl. Env. Microbiol. 72, 7431-7437. doi: 10.1128/AEM. 01559-06

Emesh, S., Rapson, T. D., Rajapakshe, A., Kappler, U., Bernhardt, P. V., Tollin, G., et al. (2009). Intramolecular electron transfer in sulfite-oxidizing enzymes: elucidating the role of a conserved active site arginine. Biochemistry 48, 2156-2163. doi: 10.1021/bi801553q

Firsova, J., Doronina, N., Lang, E., Spröer, C., Vuilleumier, S., and Trotsenko, Y. (2009). Ancylobacter dichloromethanicus sp. nov. - a new aerobic facultatively methylotrophic bacterium utilizing dichloromethane. Syst. Appl. Microbiol. 32, 227-232. doi: 10.1016/j.syapm.2009.02.002

Frigaard, N. U., and Dahl, C. (2008). "Sulfur metabolism in phototrophic sulfur bacteria," in Advances in Microbial Physiology, ed K. P. Robert (Waltham, MA: Academic Press), 103-200.

Garrity, G., Bell, J., and Lilburn, T. (2005). "Class I. Alphaproteobacteria class. nov," in Bergey's Manual ${ }^{\circledR}$ of Systematic Bacteriology, eds D. Brenner, N. Krieg, and J. Staley (New York, NY:
Springer), 1-574. doi: 10.1007/0387-29298-5_1

Goenrich, M., Bartoschek, S. Hagemeier, C. H., Griesinger, C., and Vorholt, J. A. (2002) A glutathione-dependent formaldehyde-activating Enzyme (Gfa) from Paracoccus denitrificans detected and purified via twodimensional proton exchange NMR spectroscopy. J. Biol. Chem. 277, 3069-3072. doi: 10.1074/jbc.C100 579200

Gregersen, L. H., Bryant, D. A., and Frigaard, N.-U. (2011). Mechanisms and evolution of oxidative sulfur metabolism in green sulfur bacteria. Front. Microbiol. 2:116. doi: 10.3389/fmicb. 2011.00116

Hansmeier, N., Chao, T.-C., Pühler, A., Tauch, A., and Kalinowski, J. (2006). The cytosolic, cell surface and extracellular proteomes of the biotechnologically important soil bacterium Corynebacterium efficiens YS-314 in comparison to those of Corynebacterium glutamicum ATCC 13032. Proteomics 6, 233-250. doi: 10.1002/pmic.20050 0144

Hunger, S., Schmidt, O., Hilgarth, M., Horn, M. A., Kolb, S., Conrad, R., et al. (2011). Competing formate- and carbon dioxideutilizing prokaryotes in an anoxic methane-emitting fen soil. Appl. Env. Microbiol. 77, 3773-3785. doi: 10.1128/AEM.00282-11

Jouanneau, Y., and Tabita, F. R. (1987). In vivo regulation of form I ribulose 1,5-bisphosphate carboxylase/ oxygenase from Rhodopseudomonas sphaeroides. Arch. Biochem. Biophys. 254, 290-303. doi: 10.1016/00039861(87)90105-6

Kanehisa, M., Goto, S., Sato, Y., Furumichi, M., and Tanabe, M. (2012). KEGG for integration and interpretation of large-scale molecular data sets. Nucleic Acids Res. 40, D109-D114. doi: 10.1093/ nar/gkr988

Kappler, U., Aguey-Zinsou, K. F., Hanson, G. R., Bernhardt, P. V., and McEwan, A. G. (2004). Cytochrome $\mathrm{c}_{551}$ from Starkeya novella: characterization, spectroscopic properties, and phylogeny of a diheme protein of the SoxAX family. J. Biol. Chem. 279, 6252-6260. doi: 10.1074/jbc. M310644200

Kappler, U., and Bailey, S. (2005). Molecular basis of intramolecular electron transfer in sulfite-oxidizing enzymes is revealed by high resolution structure of a heterodimeric complex of the catalytic molybdopterin subunit and a $c$-type cytochrome subunit. J. Biol. Chem.
280, 24999-25007. doi: 10.1074/jbc. M503237200

Kappler, U., Bailey, S., Feng, C. J., Honeychurch, M. J., Hanson, G. R., Bernhardt, P. V., et al. (2006) Kinetic and structural evidence for the importance of Tyr236 for the integrity of the Mo active site in a bacterial sulfite dehydrogenase. Biochemistry 45, 9696-9705. doi: 10.1021/bi060058b

Kappler, U., Bennett, B., Rethmeier, J., Schwarz, G., Deutzmann, R. McEwan, A. G., et al. (2000). Sulfite: cytochrome $c$ oxidoreductase from Thiobacillus novellus - purification, characterization and molecular biology of a heterodimeric member of the sulfite oxidase family. J. Biol. Chem. 275, 13202-13212. doi: 10.1074/jbc.275.18.13202

Kappler, U., Davenport, K., Beatson, S., Lucas, S., Lapidus, A., Copeland, A., et al. (2012). Complete genome sequence of the facultatively chemolithoautotrophic and methylotrophic alpha-Proteobacterium Starkeya novella type strain (ATCC 8093T). Stand. Genomic Sci. 7, 44-58. doi: 10.4056/sigs.3006378

Kappler, U., Friedrich, C. G., Truper, H. G., and Dahl, C. (2001). Evidence for two pathways of thiosulfate oxidation in Starkeya novella (formerly Thiobacillus novellus). Arch. Microbiol. 175, 102-111. doi: 10.1007/s002030000241

Kappler, U., and Maher, M. (2013). The bacterial SoxAX cytochromes. Cell. Mol. Life Sci. 70, 977-992. doi: 10.1007/s00018-012-1098-y

Kappler, U., and Nouwens, A. S. (2013). The molybdoproteome of Starkeya novella - insights into the diversity and functions of molybdenum containing proteins in response to changing growth conditions. Metallomics 5, 325-334. doi: $10.1039 / \mathrm{c} 2 \mathrm{mt} 20230 \mathrm{a}$

Kappler, U., Sly, L. I., and McEwan, A. G. (2005). Respiratory gene clusters of Metallosphaera sedula - differential expression and transcriptional organization. Microbiology 151, 35-43. doi: 10.1099/mic.0.27515-0

Katayama Fujimura, Y., and Kuraishi, H. (1980). Characterization of Thiobacillus novellus and its thiosulfate oxidation. J. Gen. Appl. Microbiol. 26, 357-367. doi: 10.2323/jgam.26.357

Kelly, D. P., McDonald, I. R., and Wood, A. P. (2000). Proposal for the reclassification of Thiobacillus novellus as Starkeya novella gen. nov., comb. nov., in the alphasubclass of the Proteobacteria. Int. J. Syst. Evol. Microbiol. 50, 1797-1802.
Kertesz, M. A., Fellows, E., Schmalenberger, A., and Allen, I. L. (2007). "Rhizobacteria and plant sulfur supply," in Advances in Applied Microbiology, eds A. I. Laskin, S. Sariaslani and G. M. Gadd (Waltham, MA: Academic Press), 235-268.

Kolb, S. (2009). Aerobic methanoloxidizing Bacteria in soil. FEMS Microbiol. Lett. 300, 1-10. doi: 10.1111/j.1574-6968.2009.01681.x

Kolber, Z. (2007). Energy cycle in the ocean: powering the microbial world. Oceanography 20, 79-88. doi: 10.5670/oceanog.2007.51

Larkin, J. M., Williams, P. M., and Taylor, R. (1977). Taxonomy of the genus Microcyclus Ørskov 1928: reintroduction and emendation of the genus Spirosoma Migula 1894 and proposal of a new genus, Flectobacillus. Int. J. Syst. Bacteriol. 27, 147-156. doi: 10.1099/00207713-27-2-147

Leefeldt, R. H., and Matin, A. (1980). Growth and physiology of Thiobacillus novellus under nutrient- limited mixotrophic conditions. J. Bacteriol. 142, 645-650.

Lejohn, H. B., Van-Caeseele, L., and Lees, H. (1967). Catabolite repression in the facultative chemoautotroph Thiobacillus novellus. J. Bacteriol. 94, 1484-1491.

Mandal, S., Chatterjee, S., Dam, B., Roy, P., and Das Gupta, S. K. (2007). The dimeric repressor SoxR binds cooperatively to the promoter(s) regulating expression of the sulfur oxidation (sox) operon of Pseudaminobacter salicylatoxidans KCT001. Microbiology 153, 80-91. doi: 10.1099/mic.0.29197-0

Markowitz, V. M., Chen, I.-M. A., Palaniappan, K., Chu, K., Szeto, E., Grechkin, Y., et al. (2012). IMG: the integrated microbial genomes database and comparative analysis system. Nucleic Acids Res. 40, D115-D122. doi: 10.1093/nar/ gkr1044

Matin, A., Schleiss, M., and Perez, R. C. (1980). Regulation of glucose transport and metabolism in Thiobacillus novellus. J. Bacteriol. 142, 639-644.

McCarthy, J. T., and Charles, A. M. (1974). CO2 fixation by the facultative autotroph Thiobacillus novellus during autotrophy-heterotrophy interconversions. Can. J. Microbiol. 20, 1577-1584. doi: $10.1139 / \mathrm{m} 74$ 244

Oh, J. K., and Suzuki, I. (1977a). Isolation and characterization of a membrane-associated thiosulphateoxidising system of Thiobacillus novellus. J. Gen. Microbiol. 99, 
397-412. doi: 10.1099/0022128799-2-397

Oh, J. K., and Suzuki, I. (1977b). Resolution of a membraneassociated thiosulphate-oxidising complex of Thiobacillus novellus. J. Gen. Microbiol. 99, 413-423. doi: 10.1099/00221287-99-2-413

Padden, A. N., Kelly, D. P., and Wood, A. P. (1998). Chemolithoautotrophy and mixotrophy in the thiophene2- carboxylic acid-utilizing Xanthobacter tagetidis. Arch. Microbiol. 169, 249-256. doi: 10. 1007/s002030050568

Perez, R. C., and Matin, A. (1980). Growth of Thiobacillus novellus on mixed substrates (mixotrophic growth). J. Bacteriol. 142, 633-638.

Peyraud, R., Kiefer, P., Christen, P., Portais, J.-C., and Vorholt, J. A. (2012). Co-Consumption of methanol and succinate by Methylobacterium extorquens AM1. PLOS ONE 7:e48271. doi: 10.1371/journal.pone.0048271

Raj, H. D. (1989). Oligotrophic Methylotrophs: Ancylo-bacter (Basonym, Microcyclus' òrskov) Raj gen. nov. Crit. Rev. Microbiol.17, 89-106. doi: 10.3109/104084189091 05743

Rapson, T. D., Kappler, U., and Bernhardt, P. V. (2008). Direct catalytic electrochemistry of sulfite dehydrogenase: mechanistic insights and contrasts with related
Mo enzymes. Biochim. Biophys. Acta Bioenerg. 1777, 1319-1325. doi: 10.1016/j.bbabio.2008.06.005

Ray, P., Girard, V., Gault, M., Job, C., Bonneu, M., Mandrand-Berthelot, M.-A., et al. (2013). Pseudomonas putida KT2440 response to nickel or cobalt induced stress by quantitative proteomics. Metallomics 5, 68-79. doi: 10.1039/c2mt20147j

Robertson, L. A., and Kuenen, G. J. (1983). Thiosphaera pantotropha gen. nov. sp. nov., a facultatively anaerobic, facultatively autotrophic sulphur bacterium. J. Gen. Microbiol. 129, 2847-2855.

Rother, D., Orawski, G., Bardischewsky, F., and Friedrich, C. G. (2005). SoxRS-mediated regulation of chemotrophic sulfur oxidation in Paracoccus pantotrophus. Microbiology 151, 1707-1716. doi: 10.1099/mic.0.27724-0

Starkey, R. L. (1935). Isolation of some bacteria which oxidise thiosulfate. Soil Sci. 39, 197-219. doi: 10.1097/ 00010694-193503000-00004

Stubner, S., Wind, T., and Conrad, R. (1998). Sulfur oxidation in rice field soil: Activity, enumeration, isolation and characterization of thiosulfate-oxidizing bacteria. Syst. Appl. Microbiol. 21, 569-578. doi: 10.1016/S0723-2020(98)80069-6

Tabita, F. R. (1999). Microbial ribulose 1,5-bisphosphate carboxylase/ oxygenase: a different perspective.
Photosynth. Res. 60, 1-28. doi: 10.1023/A:1006211417981

Van Dijl, J. M., and Hecker, M. (2013). Bacillus subtilis: from soil bacterium to super-secreting cell factory. Microb. Cell Fact. 12, 3. doi: 10.1186/1475-2859-12-3

Vorholt, J. A., Marx, C. J., Lidstrom, M. E., and Thauer, R. K. (2000) Novel formaldehyde-activating enzyme inMethylobacterium extorquens AM1 required for growth on methanol. J. Bacteriol. 182, 6645-6650. doi: 10.1128/JB. 182.23.6645-6650.2000

Wang, X., and Tabita, F. R. (1992). Reversible inactivation and characterization of purified inactivated from I Ribulose-1,5-Bisphosphate Carboxylase Oxygenase of Rhodobacter sphaeroides. J. Bacteriol. 174, 3593-3600.

Wilson, J. J., and Kappler, U. (2009). Sulfite oxidation in Sinorhizobium meliloti. Biochim. Biophys. Acta 1787, 1516-1525. doi: 10.1016/j.bbabio.2009.07.005

Xin, Y. H., Zhou, Y. G., and Chen, W. X. (2006). Ancylobacter polymorphus sp. nov. and Ancylobacter vacuolatus sp. nov. Int. J. Syst. Evol. Microbiol. 56, 1185-1188. doi: 10.1099/ijs.0.64118-0

Yuan, H., Ge, T., Chen, C., O’Donnell, A. G., and Wu, J. (2012). Significant role for microbial autotrophy in the sequestration of soil carbon. Appl. Env. Microbiol. 78, 2328-2336. doi: 10.1128/AEM. 06881-11

Conflict of Interest Statement: The authors declare that the research was conducted in the absence of any commercial or financial relationships that could be construed as a potential conflict of interest.

Received: 20 May 2013; accepted: 23 September 2013; published online: 17 October 2013.

Citation: Kappler $U$ and Nouwens AS (2013) Metabolic adaptation and trophic strategies of soil bacteria-C1metabolism and sulfur chemolithotrophy in Starkeya novella. Front. Microbiol. 4:304. doi: 10.3389/fmicb.2013.00304 This article was submitted to Terrestrial Microbiology, a section of the journal Frontiers in Microbiology.

Copyright (c) 2013 Kappler and Nouwens. This is an open-access article distributed under the terms of the Creative Commons Attribution License (CC BY). The use, distribution or reproduction in other forums is permitted, provided the original author(s) or licensor are credited and that the original publication in this journal is cited, in accordance with accepted academic practice. No use, distribution or reproduction is permitted which does not comply with these terms. 